\title{
Association Between the ABO Blood Types and Post-operative Pain
}

\author{
Mia Birkholm Lausten, ${ }^{1}$ Sten Rasmussen ${ }^{2}$ and Parisa Gazerani ${ }^{1}$ \\ 1. Department of Health Science and Technology, Faculty of Medicine, Aalborg University, Aalborg, Denmark; \\ 2. Department of Clinical Medicine, Aalborg University and Orthopaedic Surgery Research Unit, Aalborg University Hospital, Aalborg, Denmark
}

DOI: https://doi.org/10.17925/ENR.2018.13.1.38

A number of genetic factors such as gender and hair colour have been associated with pain. ABO blood types have been linked to a diverse range of diseases such as various types of cancer, but only two studies have investigated a possible link between ABO blood types and pain. Thus, the aim of this study was to investigate if an association exists between a certain blood type and post-operative pain. Patients (18-40 years) who had an anterior cruciate ligament (ACL) reconstruction at Aalborg University Hospital, Aalborg, Denmark between January 2012 and August 2017 were included in this retrospective study. Blood type and postoperative analgesic use were extracted from the patients' medical journals. The post-operative analgesics were converted to milligrams of morphine using equivalent doses for comparison between blood types and consumption of the analgesics. Sixty-six patients undergoing $\mathrm{ACL}$ reconstruction were divided into blood types $\mathrm{A}, \mathrm{B}$ or $\mathrm{O}$. None of the enrolled patients had AB blood type. No significant difference was found between a certain blood type and the amount of post-operative analgesics consumed $(p=0.517)$. Findings from this study demonstrated that patients undergoing ACL reconstruction with blood types $\mathrm{A}, \mathrm{B}$ and $\mathrm{O}$ were not significantly different concerning consumption of post-operative analgesics.

\section{Keywords}

ABO blood types, pain, post-operative pain, post-operative analgesics, anterior cruciate ligament $(\mathrm{ACL})$ reconstruction

Disclosure: Mia Birkholm Lausten, Sten Rasmussen and Parisa Gazerani have nothing to declare in relation to this article.

Review Process: Double-blind peer review Compliance with Ethics: All procedures were followed in accordance with the responsible committee on human experimentation and with the Helsinki Declaration of 1975 and subsequent revisions. The study was approved by the Danish Data Protection Agency and is covered under the region of Northern Jutland's umbrella-report (approval ID: 2017-192).

Authorship: All named authors meet the criteria of the International Committee of Medical Journal Editors for authorship for this manuscript, take responsibility for the integrity of the work as a whole and have given final approval for the version to be published.

open Access statement: This article is published under the Creative Commons Attribution Noncommercial License, which permits any noncommercial use, distribution, adaptation and reproduction provided the original authors and source are given appropriate credit. (c) The Authors 2018.

Received: 31 January 2018

Accepted: 26 February 2018

Citation: European Neurological

Review. 2018;13(1):38-43

Corresponding Author: Parisa Gazerani, Department of Health Science and Technology, Aalborg University, Frederik Bajers Vej 7A2-A2-208, 9220 Aalborg East, Denmark. E: gazerani@hst.aau.dk LinkedIn: linkedin.com/in/parisa-gazerani-2297122/

Support: No funding was received for conduction of this study or preparation of this article.
Acute pain is defined as an 'unpleasant, complex, dynamic psychophysiological response to tissue damage, disease or inflammation, ${ }^{1-3}$ and often lasts for a short period. ${ }^{1{ }^{14}}$ Its biological function is to minimise behaviours that may lead to reduced tissue healing. ${ }^{1,5}$ When patients are recovering from a surgery, uncontrolled acute post-operative pain often occurs, which can be damaging. Even though the understanding of pain mechanisms and the treatment of post-operative pain have improved over the years, uncontrolled post-operative pain has remained a huge health care problem. ${ }^{6,7}$ In the United States, it is estimated that up to $80 \%$ of the patients undergoing any kind of surgery report inadequate post-operative pain relief despite optimal use of oral opioids and nonopioid agents. 2,4,6,8 Seventy-five percent of those reported the level of pain to be moderate, severe

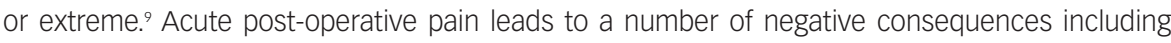
slow recovery, increased stress and anxiety, prolonged opioid use and decreased quality of life to mention a few. ${ }^{6,10}$

A study by Gerbershagen et al. 20137 investigated post-operative pain among 50,199 patients and 179 different surgical procedures and found that patients who underwent orthopaedic surgeries were among those with the highest level of post-operative pain. The intensity of pain, as measured on a numeric rating scale (0-10) indicated a mean level of 5.41 for patients with an anterior cruciate ligament $\left(\mathrm{ACL}\right.$ ) reconstruction. ${ }^{7} \mathrm{ACL}$ injuries are common and approximately 2,500 ACL reconstructions were performed in Denmark in 2015. ${ }^{11}$ They are usually related to sports and affect younger people in most cases. ${ }^{11-13}$ Shortly explained, an ACL reconstruction begins with harvesting of a graft, often a hamstring tendon graft. Afterwards, a tunnel is drilled into tibia and femur at the insertion points, which are placed near the anatomic ACL insertion points. Lastly, the graft is placed. The aim of the operation is to eliminate knee instability in patients affected by ACL rupture. ${ }^{14}$

A number of risk factors associated with acute post-operative pain have been identified. It is a complex interaction between many factors, which roughly can be divided into genetic and environmental factors. ${ }^{15-18}$ Different genes including the catechol-O-methyl-transferase and GTP cyclohydrolase genes are found important in the development of post-operative pain. ${ }^{19,20}$ Other genetic factors such as gender, ethnicity and hair colour are also associated with pain sensitivity. ${ }^{21-23}$ For instance, female gender and people of younger age were found to be associated with higher post-operative pain scores. ${ }^{17}$ Therefore, these factors must be considered when planning postoperative medication plans. A less studied factor is the association between acute post-operative pain and $A B O$ blood types. 
The ABO blood system consists of four blood types: A, B, AB and O, inherited through genes on chromosome 9 at $9 q 34.1$ and $9 q 34.2 .^{24-26}$ Antigens encoded by the $A B O$ locus define the blood types. ${ }^{26,27}$ The $A B O$ locus has three allelic forms: $A, B$ and $O$, where the $A$ and $B$ alleles encode for specific glycosyltransferases, which catalyse the transfer of carbohydrates, $\mathrm{N}$-acetylgalactosamine or D-galactose to an $\mathrm{H}$ antigen producing $\mathrm{A}$ antigen or/and $\mathrm{B}$ antigen, respectively. ${ }^{26,28}$ The $\mathrm{O}$ allele encodes for a glycosyltransferase, which is inactive and therefore the $H$ antigen remains unchanged and no antigens are produced. ${ }^{24,26-28}$ The presence or lack of antigen A or/and antigen B in red blood cells determines which blood type an individual will have. If antigen $A$ or antigen $B$ is present in the red blood cells, the person presents with blood type $A$ and $B$ respectively, whereas if both antigen $A$ and antigen $B$ are present or absent in the red blood cells, then the individual will have blood type $A B$ and $O$ respectively. ${ }^{24}$

The blood types are unequally distributed among different populations. ${ }^{26}$ However, blood type $\mathrm{O}$ is the most common blood type among all populations (White non-Hispanic, Hispanic, Black non-Hispanic, Asian and North American Indian). The ABO blood type distribution for White non-Hispanic individuals are: O: $45.2 \%, \mathrm{~A}: 39.7 \%$, B: $10.9 \%$ and AB: $4.2 \%{ }^{29}$

ABO blood type has been linked to a number of diseases, such as various types of cancer and musculoskeletal diseases. ${ }^{24,28,30-32}$ To our knowledge, no studies have investigated if a certain blood type is associated with developing post-operative pain. However, two studies investigated the association between blood type and experimental-induced pain induced by a cold pressor test. The first study found no significant difference between blood types and experimental-induced pain in healthy volunteers, ${ }^{33}$ whereas the second study found a difference between the blood types. ${ }^{34}$

Therefore, the aim of this retrospective study was to investigate if any associations exist between ABO blood types and acute post-operative pain in patients who have been through an $A C L$ reconstruction. This was done by accessing the amount of received post-operative medication and comparing it among the patients with various blood types. It was hypothesised that patients with different $\mathrm{ABO}$ blood types would present different amounts of post-operative medication, thereby indirectly reflecting having different intensities of acute post-operative pain.

\section{Methods}

\section{Study population and design}

The study was approved by the Danish Data Protection Agency and is covered under the region of Northern Jutland's umbrella-report (approval ID: 2017-192). A health care professional from Aalborg University Hospital, Aalborg, Denmark provided a list of all the patients who had an ACL reconstruction at the hospital over a time-period of January 2012 to August 2017. This retrospective study was performed by accessing the journals of 481 patients. The list contained patients' name, civil registration number (CPR-number), production hospital (Aalborg University Hospital), operation date, operation code (KNGE45), operation ward (same-day operation) and the patient's phone number. A number of inclusion and exclusion criteria were applied to include eligible patients' journals for this study (Table 1).

Patients in the age range of 18-40 years were included in the study. The patients' medical data were extracted by using the patient CPR-number to access their medical journals in Clinical Suite (version 16.0.5, 2016, CSC Scandihealth, Denmark). The patients' gender, age at the operation date, blood type and the data from their anaesthesia scheme used under the operation were extracted.
Table 1: Inclusion and exclusion criteria for including eligible patients' journals

\begin{tabular}{l}
\hline Inclusion criteria: \\
\hline ACL reconstruction \\
\hline Age: $18-40$ years \\
\hline Essential information: \\
- Gender \\
- Blood type \\
- Anaesthesia scheme from the ACL reconstruction including pre-operative, \\
daily and post-operative medication \\
- Surgery description \\
Exclusion criteria: \\
- Unavailability of essential information (according to inclusion criteria) \\
- Use of other grafts, then hamstring grafts \\
- Suffering from cancer, neurologic, cardiovascular, hormone, intestine or \\
psychological conditions \\
- Daily intake of analgesics \\
ACL = anterior cruciate ligament.
\end{tabular}

Figure 1: Flow diagram for included patients.

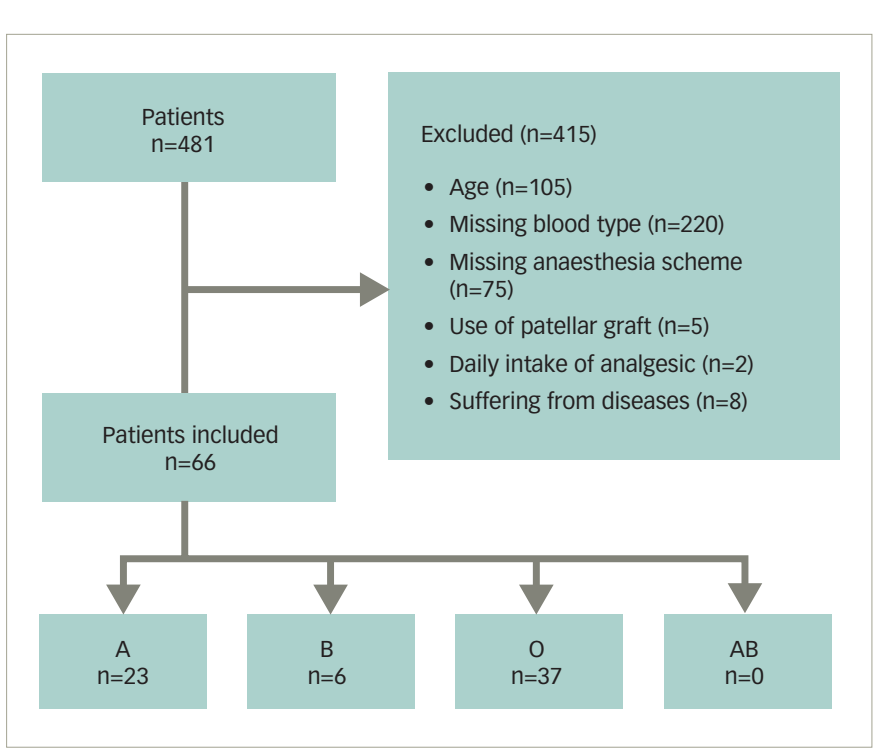

Exclusion from the study was due to age, missing information, use of patellar graft daily intake of analgesic and suffering from one of the exclusion diseases. $n=$ number of participants. Blood types are indicated as $A, B, O$ and $A B$.

The data extracted from the anaesthesia scheme included preoperation medication, daily medication, post-operative medication and if available, weight, height, alcohol intake and smoking status. Regarding use of post-operative medication, only analgesics were included based on the purpose of this study. The surgery description was examined and only patients with hamstring tendon grafts were included. Patients operated with a bone-patellar-tendon-bone (BPTB) graft were not included since a study found that BPTB grafts were associated with higher knee pain. ${ }^{35}$ Afterwards, the patients' medical journals were examined for several conditions including cancer, neurologic, cardiovascular, hormone, intestine and psychological conditions. If the patients were diagnosed with some of these conditions they were excluded from the study. Lastly, if the patients were taking analgesics on a daily basis they were excluded as well. After application of these required restrictions, 415 patients were excluded from the study (Figure 1). 
The 66 patients included in the study were anonymised after the medical data were extracted. Twenty-one of the patients had meniscus surgery contemporary with the $\mathrm{ACL}$ reconstruction but they were not excluded.

The amount of post-operative analgesics, and thereby indirectly the intensities of post-operative pain, was obtained during the patients' stay on the recovery ward right after the ACL reconstruction, often only a few hours. Morphine equivalents were used to calculate the amount of postoperative analgesics for each patient to compare post-operative pain in terms of consumption of post-operative analgesics of the different blood types. This type of calculation has already been used in a similar case. ${ }^{7}$ The conversion factors used to calculate the amount of post-operative analgesics to milligrams (mg) of oral morphine are shown in Table 2.

Due to the fact that no equivalent dose for ibuprofen was found in the literature, ibuprofen was not included in the calculation of the postoperative analgesics doses to avoid any improper calculation.

\section{Statistics}

Microsoft Excel (version 14.0.7190.5000, 2010, Microsoft, Seattle, WA, US) was used to fill in data and SPSS software (version 24, IBM, Armonk, NY, US) was used to perform the statistical analysis. All data were tested for normality with the use of the Shapiro-Wilk test. The data were non-normally distributed. Therefore, a Mann-Whitney $U$ analysis was used to test whether post-operative analgesic doses for patients that had a meniscus surgery contemporary with the ACL reconstruction differed from those who only had an ACL reconstruction. Afterwards, a Kruskal-Wallis analysis was performed to answer the primary research question - as if a difference between the various blood types and the amounts of post-operative analgesics consumed, indirectly reflecting different intensities of acute post-operative pain, existed. Lastly, to test whether gender differences in the measured parameters existed, a two-way analysis of variance (ANOVA) followed by a least significant difference (LSD) post-hoc analysis was performed. Data were considered statistically significant with $p$-value $<0.05$.

\section{Results}

\section{Demographic characteristics}

Sixty-six patients who had an ACL reconstruction at Aalborg University Hospital from January 2012 to August 2017 were included in this retrospective study. Blood types of patients were distributed as $A$ : $34.85 \%, \mathrm{~B}: 9.09 \%, 0: 56.06 \%$, and $\mathrm{AB}: 0 \%$. It is worth mentioning that only $5 \%$ of the Danish population present with blood type $A B .{ }^{40}$ There were more women (57.58\%) than men (42.42\%). The median age of the patients was 24 years: the youngest patient was 18 years old and the oldest was 37 years old.

Demographic data and medication characteristics such as gender, age, alcohol consumption, smoking status, daily medication and meniscus surgery at the same time as the ACL reconstruction, in relation to blood type are presented in Table 3.

Eighteen patients received medication on a daily basis, only three of them were men. Most of the medications registered were contraceptive pills or medication for allergic reactions. Only patients who consumed more alcohol than the recommendations made by the Danish Health Authority (i.e. 7 units for women, and 14 units for men) ${ }^{41}$ were included as 'yes' in Table 3. Eleven patients had missing smoking status, which indicates that the percentages of smokers may be higher than what is presented. The same applies for alcohol consumption where values for 12 patients were missing.
Table 2: Equivalent doses for $30 \mathrm{mg}$ of oral morphine $7,36-39$

\begin{tabular}{|l|l|}
\hline Drug agent (administration route) & Equivalents to $30 \mathrm{mg}$ oral morphine \\
\hline Morphine (oral) & $30 \mathrm{mg}$ \\
\hline Morphine (IV) & $10 \mathrm{mg}$ \\
\hline Fentanyl (IV) & $0.1 \mathrm{mg}$ \\
\hline Ketobemidone (IV) & $7.5 \mathrm{mg}$ \\
\hline Ketorolac (IV) & $25 \mathrm{mg}$ \\
\hline Pethidine (IV) & $50 \mathrm{mg}$ \\
\hline Tradolan (oral) & $150 \mathrm{mg}$ \\
\hline Paracetamol (oral) & $4,200 \mathrm{mg}$ \\
\hline
\end{tabular}

The patients received different post-operative analgesic agents at the recovery ward and to compare the doses, conversion factors were used to calculate the doses to $\mathrm{mg}$ of oral morphine. The medications were given either orally or intravenously, which is presented in italics.

IV = intravenous; $m g=$ milligrams

Figure 2: Calculated amount of post-operative analgesics among blood types $\mathrm{A}, \mathrm{B}$ and $\mathrm{O}$.

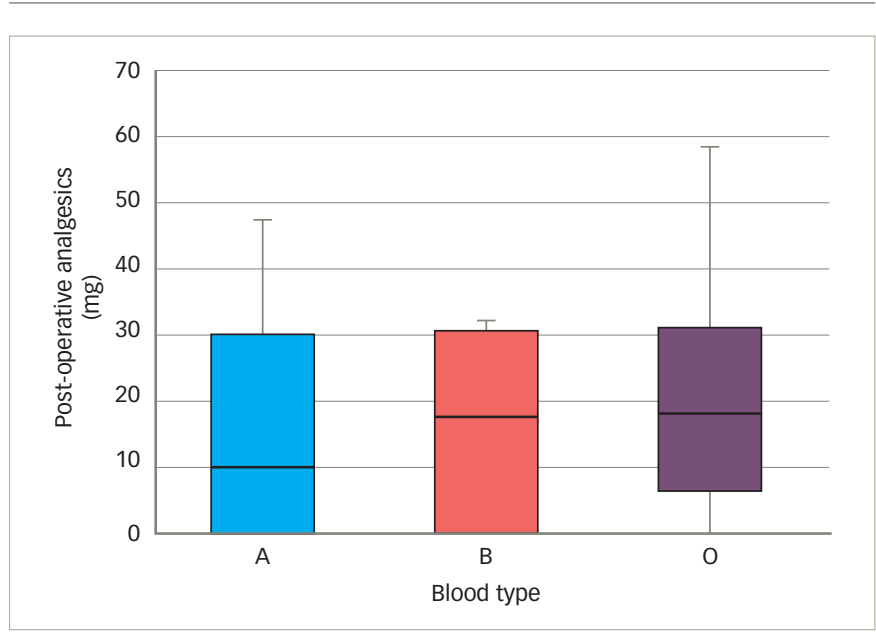

The post-operative analgesics were converted to milligrams of morphine using equivalent doses for comparison between blood types and consumption of the analgesics. This box plot presents calculated amount of post-operative analgesics ( $\mathrm{mg}$ ) among blood types $A, B$ and $O$ (median $\pm I Q R$ ). The central rectangle spans the first quartile to the third quartile (IQR). The segment inside the rectangle shows the median and whiskers above the boxes show the locations of the maximum amount consumed. $I Q R$ = interquartile range; $m g$ = milligrams.

Most of the patients received 1,000 mg paracetamol and $400 \mathrm{mg}$ ibuprofen pre-operatively, except for six patients who received paracetamol alone. Furthermore, one patient did not receive any pre-operative medication due to not being able to swallow the pills.

The equivalent calculated amount of post-operative analgesics for each blood type is presented in Figure 2.

Furthermore, 10 patients received $400 \mathrm{mg}$ of ibuprofen post-operatively, but ibuprofen was not taken into account due to lack of equivalent doses of morphine for ibuprofen in the literature. These 10 patients were identified with blood type A: 3 (13.04\%), B: 1 (16.67\%), and 0: 6 (16.22\%).

\section{Blood type and post-operative pain}

No significant difference was found between the amount of postoperative analgesics consumed and contemporary meniscus surgery in the Mann-Whitney $U$ analysis ( $p=0.374)$. Therefore, all patients were included for the Kruskal-Wallis analysis. The median values of the received post-operative analgesics indicated a difference between the ABO blood types (Figure 2). 
Table 3: Demographic and medication characteristics of the study participants $(n=66)$

\begin{tabular}{|c|c|c|c|}
\hline Features & A & B & 0 \\
\hline $\begin{array}{l}\text { Gender, n (\%) } \\
\text { Women } \\
\text { Men }\end{array}$ & $\begin{array}{l}16(69.57) \\
7(30.43)\end{array}$ & $\begin{array}{l}4(66.67) \\
2(33.33)\end{array}$ & $\begin{array}{l}18(48.65) \\
19(51.35)\end{array}$ \\
\hline $\begin{array}{l}\text { Age, years } \\
\text { Median age (minimum-maximum) }\end{array}$ & $24.0(18.0-35.0)$ & $22.5(20.0-31.0)$ & $24.0(18.0-37.0)$ \\
\hline $\begin{array}{l}\text { Smoking status, n (\%) } \\
\text { Yes } \\
\text { No } \\
\text { Previously } \\
\text { Missing values }\end{array}$ & $\begin{array}{l}3(13.04) \\
16(69.57) \\
1(4.35) \\
3(13.04)\end{array}$ & $\begin{array}{l}0(0.00) \\
4(66.67) \\
1(16.67) \\
1(16.67)\end{array}$ & $\begin{array}{l}6(16.22) \\
23(62.16) \\
1(2.70) \\
7(18.92)\end{array}$ \\
\hline $\begin{array}{l}\text { Alcohol, n (\%) } \\
\text { Yes } \\
\text { No } \\
\text { Missing values }\end{array}$ & $\begin{array}{l}1(4.34) \\
19(82.61) \\
3(13.04)\end{array}$ & $\begin{array}{l}0(0.00) \\
5(83.33) \\
1(16.67)\end{array}$ & $\begin{array}{l}0(0.00) \\
29(78.38) \\
8(21.62)\end{array}$ \\
\hline BMI, Median (minimum-maximum) & $24.84(19.00-29.39)$ & $23.57(19.00-27.22)$ & $24.09(19.73-32.69)$ \\
\hline $\begin{array}{l}\text { Pre-operative medication, n (\%) } \\
\text { Paracetamol and ibuprofen } \\
\text { Only paracetamol } \\
\text { None }\end{array}$ & $\begin{array}{l}19(82.61) \\
3(13.04) \\
1(4.34)\end{array}$ & $\begin{array}{l}6(100.00) \\
0(0.00) \\
0(0.00)\end{array}$ & $\begin{array}{l}34(91.89) \\
3(8.11) \\
0(0.00)\end{array}$ \\
\hline $\begin{array}{l}\text { Daily medication, n (\%) } \\
\text { Yes } \\
\text { No }\end{array}$ & $\begin{array}{l}4(17.39) \\
19(82.61)\end{array}$ & $\begin{array}{l}2(33.33) \\
4(66.67)\end{array}$ & $\begin{array}{l}12(32.43) \\
25(67.57)\end{array}$ \\
\hline $\begin{array}{l}\text { Meniscus surgery, n (\%) } \\
\text { Yes } \\
\text { No }\end{array}$ & $\begin{array}{l}8(34.78) \\
15(65.22)\end{array}$ & $\begin{array}{l}3(50.00) \\
3(50.00)\end{array}$ & $\begin{array}{l}10(27.03) \\
17(72.97)\end{array}$ \\
\hline
\end{tabular}

Blood types are indicated as: A, B, and O. Number (n) outside brackets, and percentages (\%) are given inside brackets. Percentages may not add up to $100.00 \%$ because of rounding. $B M I=$ body mass index.

However, the Kruskal-Wallis analysis showed no significant difference between blood type and post-operative pain, measured in amount of postoperative analgesics used (overall $p=0.517$ ). Although the mean ranks of the Kruskal-Wallis analysis of $30.17,31.75$ and 35.85 for blood types A, B and $\mathrm{O}$, respectively indicated that there was a difference between blood type $A$ and $O(p=0.256)$, and $B$ and $O(p=0.647)$, the differences were not significant. Furthermore, the median values for received post-operative analgesics indicated that blood types $A$ and $B$ were different from each other, this was however not significant $(p=0.891)$.

\section{Blood type, post-operative pain and gender}

The two-way ANOVA showed no significant gender difference (overall $\mathrm{p}=0.179$ ). The mean amount of analgesics among blood type $A$ was $22.21 \mathrm{mg}$ and $13.07 \mathrm{mg}$ for men and women, respectively. These indicated that men received a larger amount of post-operative analgesics than women. However, the LSD post-hoc analysis revealed that the difference was not significant $(p=0.206)$. The same tendency was observed for patients with blood type B. The means for blood type B were $24.00 \mathrm{mg}$ and $12.32 \mathrm{mg}$ for men and women, respectively, but they were not significantly different from each other $(\mathrm{p}=0.395)$. Among blood type $\mathrm{O}$, the amount of post-operative analgesics for men and women were closer related, with means of $20.80 \mathrm{mg}$ and $19.52 \mathrm{mg}$ for men and women, respectively $(p=0.805)$.

\section{Discussion}

This retrospective study investigated whether an association could be identified between a certain blood type and post-operative pain. Pain intensity is normally measured on a visual analogue scale (VAS). However, VAS scores were not available for a large proportion of the patients in the present study. Therefore, post-operative pain was considered based on the amount of consumed analgesics, which indirectly reflected different intensities of post-operative pain. To make this factor comparable among the patients on different analgesics, the amount of each compound was converted to number of milligram of oral morphine based on equivalent doses available in the literature. ${ }^{7,36-39}$ Findings from this study did not demonstrate any significant difference among blood types A, B and O in terms of consumption of post-operative pain analgesics. However, some tendencies were observable.

\section{Blood type and post-operative pain}

Overall, this study found no significant difference between blood types $\mathrm{A}, \mathrm{B}$ and $\mathrm{O}$ and post-operative analgesic use. Even though the groups were not significantly different from each other, a tendency for a larger amount of post-operative analgesics was observed among patients with blood type $\mathrm{O}$ as compared with patients with non-O blood types ( $\mathrm{p}=0.256$ and 0.647 for blood types $\mathrm{A}-\mathrm{O}$ and $\mathrm{B}-\mathrm{O}$ respectively). Blood types $\mathrm{A}$ and $B$ were closely related $(p=0.891)$.

Two studies investigated the association between pain and blood type on healthy volunteers using a cold pressor test..33,34 One study found a significant difference in baseline pressure pain thresholds among the $A B O$ blood types. Blood type B had the highest and blood type $A B$ had the lowest thresholds. ${ }^{34}$ If these findings can be translated into clinical pain states then it is expected that the patients with blood type B should receive a significantly lower amount of post-operative analgesics than patients with other blood types. This was, however, not the case in the present study. These findings can be due to several factors, for example, post-operative patients present different features than healthy volunteers in a short-term pain model. Another point to consider is the equal number of participants 
within each blood type for comparison, which was not achieved in this retrospective study. Generally, prospective cohorts that allow controllable inclusion of subjects for a certain purpose would yield more reliable results than retrospective data mining studies with already collected data for other purposes. However, since the global distribution of $\mathrm{ABO}$ blood types is unequal, it might still be difficult to include an equal distribution of patients within each blood type in prospective studies. ${ }^{29}$ In line with this, blood type AB was not included in this study due to the low distribution of this blood type in Northern Europe and therefore it is impossible to predict if similar results could have been found if that blood type group could have been included. Sample size is also another interfering factor. To identify differences, a larger sample size is required. Small sample size populations can present a higher variation to the point that only tendencies could be observed.

The other study ${ }^{33}$ that investigated a potential association between pain and blood type found no significant difference between blood types $A, B$ and $O$ and pressure pain thresholds. This study ${ }^{33}$ had no blood type $A B$ due to too few participants and ended with an unequal distribution among the blood types, which braces the theory that an unequal distribution of the participants among the blood types could have generated the non-significant results. In addition, smoking and alcohol consumption might have affected the results. Current smoking status has previously been associated with higher pain intensities and lower pain thresholds than non-smokers.42-44 Furthermore, a study investigated the smoking habits among 10,386 blood donors and found no association between blood type and smoking. ${ }^{45}$ If these findings can be translated to the present study then smokers should have received a larger amount of post-operative analgesics, although it was not taken in to consideration for the current analysis. Blood type $\mathrm{O}$ had the largest percentage of smokers among the blood types in this study, which may have affected the results. The larger need for post-operative analgesics for patients with blood type O could also be caused by this factor. In addition, blood type 0 was the group with the highest percentage of missing values (18.92\%), which indicates that the results might have been skewed. Alcohol consumption over the recommended quantity has previously been found associated with higher post-operative opioid intake. ${ }^{46}$ In addition, a study has found an association between blood type A and alcoholism. ${ }^{47}$ Alcohol consumption was not a large issue in the present study as only one patient reported drinking more than the recommended quantity (i.e. 7 units for women and 14 units for men). Interestingly, the patient had blood type A. The biggest limitation according to alcohol consumption was that $18.18 \%$ of the patients in the study had missing values for alcohol consumption, which might have influenced the results due to a possible skewness generated from these missing values.

\section{Blood type, post-operative pain and gender}

Overall, no significant gender difference was found in association with post-operative analgesic use within each blood type. A recent study has found a significant gender difference, with men having higher pressure pain thresholds than women among those with blood type $B{ }^{34}$ Hence, the present study expected a significant difference between genders, with women receiving a larger amount of postoperative analgesics than men. However, this was not the case; a tendency was observed of men receiving a larger amount of postoperative analgesics than women among those with blood types A and $\mathrm{B}$. One must consider that blood type $\mathrm{O}$ had a higher percentage of men than women (Table 3), the opposite of both A and B, and this might have affected the results.
The unequal distribution of men and women within each blood type as well as other factors including daily medication might have affected the results of the present study. Larger cohorts can reveal if this finding is a false negative or positively true.

\section{Potential underlying mechanisms of the association between blood type and the amount of post- operative analgesics}

The particular design of this study does not allow for determining potential underlying mechanisms that can cause some of the tendencies observed in regard to blood type and amount of analgesics used in postoperative patients. Some hypotheses, however, have been put forward based on the previous findings in the literature. For instance, certain dietary options have been proposed based on blood types. The diet for individuals with blood type $\mathrm{O}$ included a lot of animal protein whereas the diet for individuals with blood type A includes a vegetarian diet type with fruit and vegetables being the major components. The diet for individuals with blood type $B$ proposes a large amount of dairy products and individuals with blood type $A B$ have been proposed to follow a diet combining the diet for blood type $A$ and $B$, which includes a large amount of fruit and vegetables and dairy products. ${ }^{48}$ Studies have found that a reduction in intake of poorly absorbed, short-chain carbohydrates including lactose, free fructose, and galacto-oligosaccharides resulted in a significant decline in pain (measured as VAS score) in chronic pain patients ${ }^{49}$ and a high-fat diet has been found associated with increased pain behaviour in rats. ${ }^{50}$ It is impossible to discern which diet the patients enrolled in this retrospective study have followed, but it is not unlikely that some patients have been on a particular diet or ABO-blood type diet that might have influenced their pain and thereby need for analgesics. It would be valuable to consider this point for future studies of pain research and $\mathrm{ABO}$ blood type association with pathogenesis including pain. Another theory is that glycosyltransferases involved in synthesis of ABO blood type may contribute to different nociceptive patterns as the glycosyltransferases also are involved in nerve myelination. ${ }^{51-53}$

\section{Study limitations and future perspectives}

There are some limitations to this study that one needs to consider before drawing any firm conclusion. The study was a retrospective study and this may introduce some bias in the outcome. This limitation is due to the fact that retrospective studies provide data that have not been collected for a certain hypothesis and thus many variables that can be included and controlled in prospective studies would be lacking. The relative small sample size and the unequal number of patients in each blood type might have influenced the power of this study. However, this limitation is not limited to the present study, as it actually originates from an unequal global distribution of the various blood types..$^{29}$ It turned out that none of the included patients presented with blood type $A B$ and only $9.09 \%$ of the participants presented with type $B$, which is close to the global distribution of $10.9 \% .{ }^{29}$ As the first clinical study, it was still worthwhile to attempt to identify if any association exists between $\mathrm{ABO}$ blood groups and postoperative pain to stimulate further interest for conduction of larger cohorts.

The amounts of post-operative analgesics were calculated to oral morphine with the help of equivalent doses, and due to no existence of an equivalent dose of ibuprofen to morphine, ibuprofen was not incorporated in the analysis. The calculation of post-operative analgesics may itself have influenced the results but leaving out the ibuprofen may have also twisted the outcome. As this study only tested the post-operative pain right after an ACL reconstruction, it is difficult to know if the type and amount of medication given under the surgery could have affected the received amount of post-operative analgesics. As mentioned earlier, this study 
carried many missing values for smoking status and alcohol consumption, which may also have influenced the findings. If a similar study were to be performed, it would be preferable with an equal sample size among the blood types considering equal number from each gender. In addition, it would be interesting to investigate post-operative pain within another patient group where the patients were hospitalized for a longer period, though with less comorbidities that require them to consume nonanalgesic medications. Furthermore, VAS scores for the intensity of postoperative pain can also be useful to include in future studies. This would directly indicate the pain intensity compared with the indirect method used in the present study, i.e. by calculating the amount of post-operative analgesics use, which was due to lack of accessibility to VAS data.

\section{Conclusion}

This study found no significant difference between post-operative pain - measured indirectly by the amount of post-operative analgesics consumed - and blood types $A, B$ and $O$ in patients who had an $A C L$ reconstruction. However, a tendency was observed with a larger amount of post-operative analgesics consumed by patients with blood type 0 than patients with non-O blood types. No significant difference between genders was found, but a tendency of men receiving a larger amount of post-operative analgesics than women was found in blood types $A$ and $B$. To verify the results, further research is needed, as this study had some limitations e.g. small sample size, some missing data, and unequal distribution of patients among the blood types. $]$
1. Chapman $\mathrm{CR}$, Vierck $\mathrm{CJ}$. The transition of acute postoperative pain to chronic pain: an integrative overview of research on mechanisms. J Pain. 2017;18:e1-359.

2. Meeks NM, Glass JS, Carroll BT. Acute pain management in dermatology: mechanisms and pathways. J Am Acad Dermatol. 2015;73:533-40

3. International Association for the Study of Pain. IASP Taxonomy. 2017. Available at: www.iasp-pain.org/ Taxonomy?navitemNumber=576\#Pain (accessed 7 December 2017).

4. Brennan TJ. Pathophysiology of postoperative pain. Pain. 2011:152(3 Suppl.):S33-40.

5. Henderson LA, Keay KA. Imaging acute and chronic pain in the human brainstem and spinal cord Neuroscientist. 2017:24:84-96.

6. Gan TJ. Poorly controlled postoperative pain: prevalence, consequences, and prevention. J Pain Res. 2017;10:2287-98.

7. Gerbershagen $\mathrm{HJ}$, Aduckathil S, van Wijck AJ, et al. Pain intensity on the first day after surgery: a prospective cohort study comparing 179 surgical procedures. Anesthesiology. 2013;118:934-44

8. Kharasch ED, Brunt LM. Perioperative opioids and public health Anesthesiology. 2016;124:960-5.

9. Chou R, Gordon DB, de Leon-Casasola OA, et al. Management of postoperative pain a clinical practice guideline from the American Pain Society, the American Society of Regional American Pain socicty, the American society of Regional Anesthesia and Pain of Anesthesiologists Commiteo on regional anesthesia, Executive Comm

10. Gillaspie M. Better pain management after total join replacement surgery: a quality improvement approach. Orthop Nurs. 2010;29:20-4.

11. SAKS - Dansk Selskab for Artroskopisk Kirugi og Sportstraumatologi. Årsreport 2016 - ACL reconstruktioner i Danmark. 2016. Available at: http://saks.ortopaedi.dk/wpcontent/uploads/2017/07/DKRR_Aarsrapport_2016_final.pdf (accessed 7 March 2018).

12. Azus A, Teng HL, Tufts $L$, et al. Biomechanical factors associated with pain and symptoms following anterior cruciate ligament injury and reconstruction. PM R. 2017:10:56-63.

13. Itoigawa $Y$, Takazawa $Y$, Maruyama $Y$, et al. A new technique of surgical planning for anterior cruciate ligament reconstruction: feasibility assessment of shear wave elastography to tendon of semitendinosus muscle Clin Anat 2017. DOl: 10.1002/ca 23000

14. Spindler KP, Wright RW. Clinical practice. Anterior cruciate ligament tear. N Eng/ J Med. 2008;359:2135-42.

15. Kehlet $H$, Jensen $T S$, Woolf $C J$. Persistent postsurgical pain: risk factors and prevention. Lancet. 2006;367:1618-25.

16. Sommer M, de Rijke JM, van Kleef M, et al. Predictors of acute postoperative pain after elective surgery. Clin J Pain. 2010;26:87-94.

17. Gerbershagen HJ, Pogatzki-Zahn E, Aduckathil S, et al. Procedure-specific risk factor analysis for the development of severe postoperative pain. Anesthesiology. 2014;120: 1237-45.

18. Carr AC, McCall C. The role of vitamin $\mathrm{C}$ in the treatment of pain: new insights. J Trans/ Med. 2017;15:77.

19. Belfer I, Greco CM, Lokshin A, et al. The design and methods of genetic studies on acute and chronic postoperative pain in patients after total knee replacement. Pain Med. 2014;15: 1590-602.

20. Diatchenko L, Nackley AG, Slade GD, et al. Catechol-Omethyltransferase gene polymorphisms are associated with multiple pain-evoking stimuli. Pain. 2006:125:216-24.

21. Edwards $C L$, Fillingim RB, Keefe F. Race, ethnicity and pain. Pain. 2001:94:133-7.

22. Fillingim RB, Wallace MR, Herbstman DM, et al. Genetic contributions to pain: a review of findings in humans. Oral Dis. 2008; 14:673-82.

23. Gradwohl SC, Aranake A, Abdallah AB, et al. Intraoperative awareness risk, anesthetic sensitivity, and anesthetic management for patients with natural red hair: a matched cohort study. Can J Anaesth. 2015;62:345-55.

24. Huang JY, Wang R, Gao YT, Yuan JM. ABO blood type and the risk of cancer - findings from the Shanghai Cohort Study. PLoS One. 2017;12:e0184295. DOI: 10.1371/journal.pone.0184295.

25. Meo SA, Rouq FA, Suraya F, Zaidi SZ. Association of ABO and Rh blood groups with type 2 diabetes mellitus. Eur Rev Med Pharmacol Sci. 2016:20:237-42.

26. Dean L, ABO Blood Group. In: Pratt V, McLeod H, Dean L, et al (eds). Medical Genetics Summaries, Bethesda: National Center for Biotechnology Information (US), 2012

27. Mitra R, Mishra N, Rath GP. Blood groups systems. Indian Anaesth. 2014;58:524-8.

28. Amundadottir L, Kraft P, Stolzenberg-Solomon RZ, et a. Genome-wide association study identifies variants in the ABO locus associated with susceptibility to pancreatic cancer. Nat Genet. 2009;41:986-90.

29. Garratty G, Glynn SA, McEntire R, Retrovirus epidemiology donor study. $\mathrm{ABO}$ and $\mathrm{Rh}(\mathrm{D})$ phenotype frequencies of different racial/ethnic groups in the United States. Transfusion. 2004;44:703-6.

30. Lee DH, Lee HD, Yoon SH. Relationship of ABO blood type on rotator cuff tears. PM R. 2015;7:1137-41.

31. Li B, Tan B, Chen C, et al. Association between the ABO blood group and risk of common cancers. J Evid Based Med 2014:7.79-83.

32. Kujala UM, Järvinen $\mathrm{M}$, Natri $\mathrm{A}$, et al. $\mathrm{ABO}$ blood groups and musculoskeletal injuries. Injury. 1992;23:131-3.

33. Shankar N, Gautam S, Rajkumari R, Goel G. Do blood groups influence our pain perception? Indian J Physiol Pharmacol. 2011;55:378-80.

34. Simoni AH, Jerwiarz A, Randers A, Gazerani P. Association between $\mathrm{ABO}$ blood types and pain perception. Somatosen Mot Res. 2017;34:258-64.

35. Connaughton AJ, Geeslin AG, Uggen CW. All-inside ACL reconstruction: how does it compare to standard $A C L$ reconstruction techniques? J Orthop. 2017;14:241-6

36. Pro medicin. Rene agonister. 2017. Available at: http://pro. medicin.dk/Laegemiddelgrupper/Grupper/227010\#a000 (accessed 7 December 2017).

37. Shaheen $P E$, Walsh $D$, Lasheen $W$, et al. Opioid equianalgesic tables: are they all equally dangerous? J Pain Symptom Manage. 2009;38:409-17.

38. Patanwala AE, Duby J, Waters D, Erstad BL. Opioid conversions in acute care. Ann Pharmacother. 2007:41:255-66.

39. Zeidan A, Mazoit JX, Ali Abdullah M, et al. Median effective dose (ED50) of paracetamol and morphine for postoperative pain: (ED50) of paracetamol and morphine for postoperati

40. De danske bloddonorer. Blodtyper. 2017. Available at: https:// bloddonor.dk/fakta-om-blod/blodtyper/ (accessed 7 December 2017).

41. Sundhedsstyrelsen. Sundhed og livsstil - Alkohol. 2017. Available at: www.sst.dk/da/sundhed-og-livsstil/alkoho (accessed 3 December 2017).

42. Shen L, Wei K, Chen Q, et al. Decreased pain tolerance before surgery and increased postoperative narcotic requirements in abstinent tobacco smokers. Addict Behav. 2018;78:9-14.

43. Jakobsson U, Larsson C. Smoking and chronic pain among people aged 65 years and older. Pain Pract. 2014;14:237-44.

44. Duan G, Guo S, Zhang Y, et al. Effects of epidemiological factors and pressure pain measurements in predicting postoperative pain: a prospective survey of 1,002 Chinese patients. Pain Physicion. 2017:20:E903-14.

45. Bourke GJ, O'Riordan JP. Distribution of ABO and rhesus blood groups in relation to smoking habit. Br J Prev Soc Med. 1964;18:109-13.

46. Kao SC, Tsai HI, Cheng CW, et al. The association between frequent alcohol drinking and opioid consumption after abdominal surgery: a retrospective analysis. PLOS One. 2017;12:e0171275. DOI: 10.1371/journal.pone.0171275.

47. Gleibermann L, Gershowitz H, Harburg E, Kuusinen S. Blood groups and alcohol use. I Stud Alcohol. 1981;42:557-63.

48. Wang J, García-Bailo B, Nielsen DE, El-Sohemy A. ABO genotype, 'blood-type' diet and cardiometabolic risk factors. PLOS One. 2014;9:e84749. DOI: 10.1371/journal.pone.0084749.

49. Marum AP, Moreira C, Saraiva F, et al. A low fermentable oligodi-mono saccharides and polyols (FODMAP) diet reduced pain and improved daily life in fibromyalgia patients. Scand I Pain. 2016;13:166-72.

50. Song Z, Xie W, Chen S, et al. High-fat diet increases pain behaviors in rats with or without obesity. Sci Rep. 2017;7:10350

51. Alfaro JA, Zheng RB, Persson $M$, et al. ABO(H) blood group $A$ and $B$ glycosyltransferases recognize substrate via specific conformational changes. J Biol Chem. 2008;283:10097-108.

52. Shen $\mathrm{A}$, Wang $\mathrm{H}$, Zhang $\mathrm{Y}$, et al. Expression of beta-1,4galactosyltransferase II and $\mathrm{V}$ in rat injured sciatic nerves. Neurosci Lett. 2002;327:45-8.

53. Koscielak J. A hypothesis on the biological role of ABH, Lewis and $\mathrm{P}$ blood group determinant structures in glycosphingolipids and glycoproteins. Glycoconj J. 1986;3:95-108. 